\section{Commentary: Thoracoabdominal aneurysm repair: Not for the faint of heart - or is it?}

\author{
Charles M. Wojnarski, MD, MS
}

Ando and colleagues ${ }^{1}$ describe their management of a 16-year-old patient with Marfan syndrome and concomitant aneurysmal degeneration of the descending thoracic aorta (chronic dissection after mechanical Bentall repair) and dilated cardiomyopathy with very severely reduced ejection fraction $(<10 \%)$. They successfully performed an extent II open thoracoabdominal aneurysm repair with the ultimate goal of candidacy for durable left ventricular assist device as a bridge to cardiac transplantation.

Almost immediately after the first failed cardiac transplant by Dr Wada in 1968, cardiac transplantation in Japan was subject to a moratorium from 1968 to $1998 .^{2}$ For various cultural, religious, and ethical reasons, brain death was not recognized as a concept until legislation passed in 1997 to establish it as a criterion for organ donation. Because of this delay in adoption and continued cultural and religious opposition, only 30 to 45 heart transplants occurred annually in Japan during 2014 - a country with a population of about 130 million people. ${ }^{3}$ Some might question the order of intervention in this specific patient, citing that heart transplantation, followed by open thoracoabdominal aneurysm repair, would be the most likely order of operations to result in long-term survival. Yet for regulatory reasons, the patient's clinical history unfolded as described. Fortunately, in the presently reported case, the end result was successful.

\footnotetext{
From the Division of Cardiovascular and Thoracic Surgery, Department of Surgery, Duke University Medical Center, Durham, NC.

Disclosures: The author reported no conflicts of interest.

The Journal policy requires editors and reviewers to disclose conflicts of interest and to decline handling or reviewing manuscripts for which they may have a conflict of interest. The editors and reviewers of this article have no conflicts of interest.

Received for publication Feb 7, 2021; revisions received Feb 7, 2021; accepted for publication Feb 17, 2021; available ahead of print Feb 20, 2021.

Address for reprints: Charles M. Wojnarski, MD, MS, Division of Cardiovascular and Thoracic Surgery, Department of Surgery, Duke University Medical Center, 2301 Erwin Rd, Durham, NC 27710 (E-mail: charles.wojnarski@duke.edu).

JTCVS Techniques 2021;7:49-50

2666-2507

Copyright (C) 2021 The Authors. Published by Elsevier Inc. on behalf of The American Association for Thoracic Surgery. This is an open access article under the CC BY-NCND license (http://creativecommons.org/licenses/by-nc-nd/4.0/).

https://doi.org/10.1016/j.xjtc.2021.02.019
}

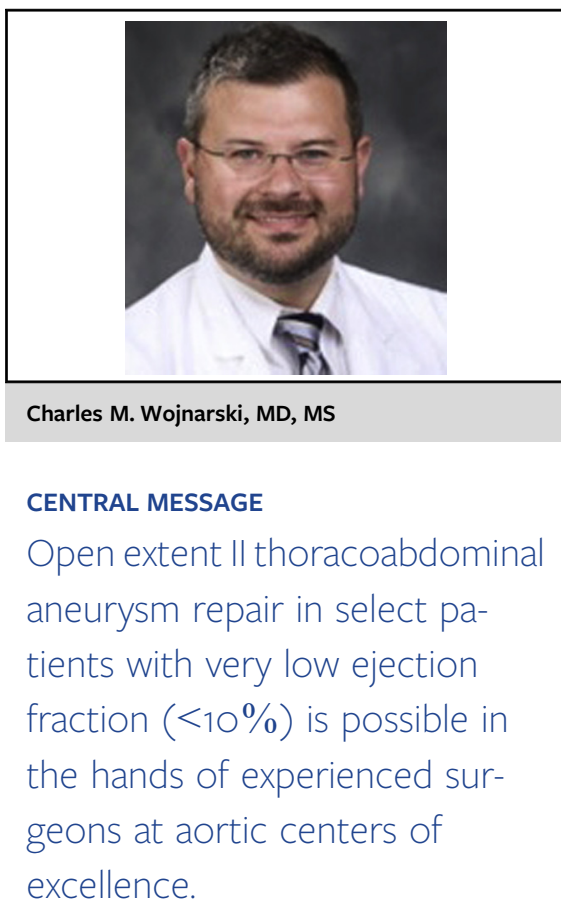

Other than the excellent preoperative planning and postoperative critical care management of patients, there are 2 important technical aspects of the procedure described by the authors that warrant highlighting: myocardial protection and cerebral protection.

Generally, cardioplegia is not utilized in standard extent I or II thoracoabdominal aneurysm repair via left thoracoabdominal incision because the ascending aorta is not accessible for antegrade delivery with crossclamp, nor is the coronary sinus for retrograde delivery. Most surgeons utilize hypothermia to $18^{\circ} \mathrm{C}$ alone as myocardial protection during a short period of deep hypothermic circulatory arrest (DHCA). In this report, the authors employ an occlusive balloon within the patient's previous ascending aortic graft to deliver antegrade cardioplegia. Only 1 small, historical, randomized controlled trial compared cold cardioplegia with hypothermia alone for myocardial protection and found improved cardiac function and less evidence of myocardial injury in the cold cardioplegia group. ${ }^{4}$ Delivery of antegrade cardioplegia with an occlusive balloon in the ascending aorta of a patient with Marfan syndrome might not be recommended given the risk of overinflation and dissection, but in the setting of a previous ascending aortic replacement it is a novel method that might have contributed to this patient's successfully cardiac recovery.

The authors also reported use of retrograde cerebral circulation for cerebral protection during the period of 
DHCA for proximal anastomosis. During DHCA, they maintained lower body oxygenated arterial perfusion via the iliac artery, which after passing through end-organ capillaries, resulted in return of oxygenated cold blood to systemic veins with a central venous pressure of 20 to $25 \mathrm{~mm}$ $\mathrm{Hg}$. This is in contrast to retrograde cerebral perfusion, which is a direct perfusion of cold blood through a superior vena caval cannula. Retrograde cerebral perfusion has been well studied with excellent evidence to support similar cerebral protection compared with antegrade cerebral perfusion in the setting of aortic arch surgery. ${ }^{5}$ The method of passive retrograde circulation during lower body arterial perfusion described by the current case study is in need of future peer-reviewed experimental and clinical data.

The authors are to be congratulated on the excellent outcome of their methodical operative planning and execution and undoubtedly meticulous postoperative care.
Although young, high-risk patients such as the 1 described above present rarely, successful outcomes depend on the high volume and experience of aortic surgeons routinely performing open thoracoabdominal repair.

\section{References}

1. Ando M, Yamauchi H, Hoshino Y, Ono M. Thoracoabdominal aorta replacement for a patient with Marfan syndrome with poor left ventricular function. J Thorac Cardiovasc Surg Tech. 2021;7:45-8.

2. Perloff JK. Heart transplantation in Japan: a historical precis. Am J Cardiol. 2012; 110:142.

3. Nakatani T, Fukushima N, Ono M, Saiki Y, Matsuda H, Nunoda S, et al. The registry report of heart transplantation in Japan (1999-2014). Circ J. 2016;80: 44-50.

4. Conti VR, Bertranou EG, Blackstone EH, Kirklin JW, Digerness SB. Cold cardioplegia versus hypothermia for myocardial protection. Randomized clinical study. J Thorac Cardiovasc Surg. 1978;76:577-89.

5. Hameed IM, Rahouma FM, Khan M, Wingo M, Demetres M, Tam DY, et al. Cerebral protection strategies in aortic arch surgery: a network meta-analysis. $J$ Thorac Cardiovasc Surg. 2020;15:18-31. 